\title{
CORRUPCIÓN, TRANSPARENCIA Y PARTICIPACIÓN POLÍTICA EN COLOMBIA*
}

\author{
Julián Arévalo Bencardino \\ Andrea Garcia Albarracin ${ }^{\mathrm{b}}$ \\ David Ortiz Escobar
}

*DOI: https.//doi.org/10.18601/01245996.v24n.46.08 Este artículo es una adaptación y ampliación de la tesis de grado presentada por Andrea García para obtener el título de Economista. Recepción: 10-10-2021, modificación final: 20-10-2021, aceptación: 29-11-2021. Sugerencia de citación: Arévalo B, J., García A. A. y Ortiz E. D. (2022). Corrupción, transparencia y participación política en Colombia. Revista de Economía Institucional, 24(46), 133-166.

a Doctor en Ciencia Política. Decano de la Facultad de Economía, Universidad Externado de Colombia, Bogotá, [julian.arevalo@uexternado.edu.co].

b Magíster en Economía. profesora e investigadora, Facultad de Economía, Universidad Externado de Colombia, Bogotá, [andrea.garcia@uexternado.edu. co], [https://orcid.org/0000-0002-2905-7217].

Doctor en Economía, profesor e investigador, Facultad de Economía, Universidad Externado de Colombia, Bogotá, [david.ortiz@uexternado.edu. co], [https://orcid.org/0000-0002-0433-517x]. 


\section{Corrupción, transparencia y participación política en Colombia}

Resumen Este trabajo estudia la relación de la percepción de corrupción y de falta de transparencia con las preferencias por el voto y la protesta. Examina el caso de Colombia con datos de la Encuesta Latinobarómetro 2015 y un modelo logístico multinomial que supone una elección simultánea del tipo de participación (o una combinación de tipos), lo que permite establecer si la preferencia por la protesta sustituye o complementan la preferencia por el voto. Se encontró una relación positiva entre la percepción de corrupción y de falta de transparencia con la preferencia de protestar además de votar. Si los ciudadanos perciben una mayor corrupción o dudan de la transparencia del gobierno están más dispuestos a participar en manifestaciones, sin reducir su apoyo a la participación electoral. Esto sugiere que hay una aceptación general de la participación democrática formal a pesar de las deficiencias del régimen político.

Palabras clave: política contenciosa, protesta, participación política, corrupción, transparencia; JEL: C51, D72, D84, H83, Z18

\section{Corruption, transparency and political participation in Colombia}

Abstract This paper studies the relationship of the perception of corruption and lack of transparency with voting preferences and protests. It examines the case of Colombia using data from the 2015 Latinobarómetro Survey and a multinomial logistic model that assumes a simultaneous choice of participation type (or a combination of types), which allows us to establish whether the preference for protest substitutes or complements the preference for voting. A positive relationship was found between the perception of corruption and lack of transparency with the preference to protest in addition to voting. If citizens perceive greater corruption or doubt government transparency, they are more willing to participate in demonstrations, without reducing their support for electoral participation. This suggests that there is a general acceptance of formal democratic participation despite the shortcomings of the political regime.

Keywords: Contentious politics, protest, political participation, corruption, transparency; JEL: C51, D72, D84, H83, Z18

\section{Corrupção, transparência e participação política na Colômbia}

Resumo Este trabalho estuda a relação entre a percepção de corrupção e falta de transparência com preferências por votar e protestar. Analisa o caso da Colômbia com dados da Pesquisa Latinobarómetro 2015 e um modelo logístico multinomial que pressupõe uma escolha simultânea do tipo de participação (ou uma combinação de tipos), o que permite estabelecer se a preferência pelo protesto substitui ou complementa a preferência pelo voto. Foi encontrada uma relação positiva entre a percepção da corrupção e a falta de transparência com a preferência pelo protesto além do voto. Se os cidadãos percebem uma maior corrupção ou duvidam da transparência do governo, eles estão mais dispostos a participar das manifestações, sem reduzir seu apoio à participação eleitoral. Isso sugere que há uma aceitação geral da participação democrática formal, apesar das deficiências do regime político.

Palavras-chave: política contenciosa, protesto, participação política, corrupção, transparência; JEL: C51, D72, D84, H83, Z18 
E n 2019, Latinoamérica presenció una ola de protestas sin precedentes, incluso en países con bajos niveles históricos de movilización social. En Bolivia, las acusaciones de corrupción en las elecciones presidenciales motivaron movilizaciones ciudadanas que resultaron en la renuncia del presidente Evo Morales (Miranda, 2019); en Chile y Ecuador, el descontento con políticas económicas y sociales causó un estado de protesta permanente durante varias semanas (Lissardy, 2019), lo que motivó, para el caso de Chile, el desarrollo de una agenda de reformas profundas a través de una nueva constitución; en Colombia, la insatisfacción de diferentes sectores sociales por las políticas del presidente Iván Duque fue canalizada a través de un "paro nacional" que duró varios días y que se caracterizó por movilizaciones ciudadanas no vistas en varias décadas (Miranda, 2019). Además, países como Perú, Nicaragua y Venezuela presenciaron desde 2018 protestas sociales en contra de la corrupción y del deterioro de sus regímenes políticos (Rojas, 2018; DW, 2018a y 2018b).

Aunque las protestas obedecieron a diferentes motivos, algunos medios las calificaron como una "Primavera latinoamericana" (CNN, 2019). En efecto, el crecimiento de la movilización ciudadana en Latinoamérica tiene causas estructurales transversales, como el aumento de la clase media, la mayor conectividad de la población y la mayor circulación de información (Castañeda, 2016). La conflictividad social aparece también como una forma de defender los derechos ciudadanos y expresar la insatisfacción con el régimen político, debido a la existencia de demandas ciudadanas no canalizadas, además de desconfianza, descontento y rabia porque se percibe que las clases dirigentes priorizan los intereses privados sobre los públicos.

Ejemplo de lo anterior es la reacción ciudadana frente a los casos de corrupción que durante varios años han acaparado los titulares de prensa. Estos escándalos van desde problemáticas de cada país, hasta casos que han trascendido las fronteras como el de los "Panama $\mathrm{Pa}$ pers" que reveló esquemas existentes para ocultar activos (BBC News, 2016), o los de Petrobras y Odebrecht (Gallas, 2019), multinacionales que ofrecieron sobornos para obtener contratos multimillonarios. La corrupción ha sido uno de los grandes detonantes de la protesta ciudadana en el continente porque deja en evidencia la incapacidad que tienen los gobiernos de defender los intereses comunes y de preservar los niveles de coherencia y autonomía en las instituciones políticas. Para Castañeda (2016), "el público latinoamericano ya no está preparado para tolerar la deshonestidad sistemática de sus gobiernos" (p. 152), sino que, por el contrario, la nueva clase media 
latinoamericana usa sus libertades para expresar su frustración con el régimen.

Sin embargo, aunque la participación democrática no institucionalizada a través de instrumentos como la protesta puede ser positiva, también es síntoma del deterioro de las instituciones políticas y de los canales democráticos convencionales. En efecto, la protesta social es una muestra de que las instituciones son incapaces de adaptarse a los cambios con facilidad y de enfrentarse a choques externos como los reclamos y las exigencias sociales (Huntington, 1965). Lo anterior es más preocupante en Latinoamérica, donde se ha puesto en duda la legitimidad y viabilidad de la democracia como régimen político, como lo demuestra lo que ha sucedido en países como Nicaragua o Venezuela, donde llegaron al poder presidentes con ambiciones hegemónicas, capaces de obtener el control de instituciones débiles, tribunales dóciles y agencias con baja capacidad de control sobre el ejecutivo (Mainwaring y Pérez, 2015).

Dado que en América Latina la utilización de la protesta está relacionada de manera directa con los altos niveles de corrupción y falta de transparencia, cabe preguntarse si existe una relación entre la percepción ciudadana de corrupción y otras formas de participación política diferentes a la protesta, como la partición electoral. La importancia de revisar esta relación se debe a que la corrupción, sumada con la movilización ciudadana, tiene el potencial de profundizar el detrimento de las instituciones y amenazar con generar un proceso de inestabilidad y decadencia política (Fukuyama, 2014), el cual podría contrarrestarse con mayor facilidad si existe un alto nivel de apoyo ciudadano a la democracia, y, particularmente, a figuras participativas convencionales como el voto.

El presente trabajo desarrolla un análisis empírico que busca estudiar la relación existente entre la percepción ciudadana de corrupción y falta de transparencia con las preferencias por los mecanismos de participación democrática como el voto y la protesta. Para ello, el artículo aborda el caso concreto de Colombia y se apoya en los datos recolectados por la encuesta de Latinobarómetro de 2015. A diferencia de otras investigaciones sobre el tema, se emplea un modelo logístico multinomial en donde se asume que los ciudadanos escogen un mecanismo de participación (o una combinación de varios) de manera simultánea, lo que permite establecer si la preferencia por la protesta sustituye a la preferencia por el voto o la complementa.

El estudio arroja evidencia a favor de una relación positiva entre la percepción ciudadana de corrupción y falta de transparencia con las 
preferencias por participar a través de la protesta complementariamente a participar a través del voto. Es decir, a medida que los ciudadanos perciben mayores niveles de corrupción, van a tender a utilizar cada vez más mecanismos de participación como la protesta, sin que esto afecte el apoyo a la participación electoral. En este sentido, los escándalos de corrupción pueden exacerbar la movilización social, lo que puede amenazar la legitimidad y estabilidad de las instituciones políticas. Sin embargo, para el caso específico de Colombia, también hay evidencia de un apego al sistema electoral del cual se infiere un arraigo a los mecanismos formales de participación democrática.

El documento se divide en cinco secciones, incluyendo esta introducción. En la segunda se presentan algunos de los enfoques teóricos que explican cómo el descontento con el desempeño de las instituciones políticas se relaciona con la política contenciosa y se resume la literatura empírica que explora la relación entre corrupción y participación democrática. La tercera sección presenta el contexto colombiano, enfatizando las dimensiones de participación democrática, corrupción y transparencia. La cuarta sección presenta el análisis empírico que relaciona los niveles de percepción de corrupción y transparencia con las formas de participación política. Posteriormente se discuten estos resultados desde la perspectiva de la consolidación de la democracia y el peligro de la decadencia política, que resulta cada vez más latente en el escenario del posconflicto colombiano.

\section{DESCONTENTO CON EL DESEMPEÑO DEL RÉGIMENY POLÍTICA CONTENCIOSA: TEORÍA Y EVIDENCIA EMPÍRICA}

Existe un amplio consenso académico alrededor de la idea de que la legitimidad es un requisito fundamental para el funcionamiento y estabilidad del régimen democrático (Easton, 1975; Kriele, 1988; Lipset, 1994). Alguna literatura reciente vincula la legitimidad con los resultados políticos y el cumplimiento de las expectativas ciudadanas. Por ejemplo, Norris (2011) aborda el problema de la legitimidad de las democracias a través del concepto de déficit democrático, el cual puede ser entendido como la brecha entre las aspiraciones y las satisfacciones que los ciudadanos demandan, y sus percepciones sobre lo que reciben de la democracia, su funcionamiento y resultados. Así, Norris identifica como fuentes potenciales de variabilidad en el lado de la oferta tres dimensiones del desempeño del régimen: 1) desempeño de los procesos, 2) desempeño de la política y 3) estructuras institucionales. 
Desde esta perspectiva, la ilegitimidad política se presenta cuando las autoridades y estructuras que conforman el Estado no cumplen con sus obligaciones y, más importante aún, cuando existe una brecha entre los resultados de su desempeño y las expectativas ciudadanas. Lo anterior puede presentarse debido a factores como la preferencia de los intereses privados en la realización de normas y políticas públicas, la elección y nombramiento de representantes que tienen vínculos con la economía ilegal, la corrupción administrativa, la estructuración del sistema democrático a partir de relaciones clientelares y la falta de transparencia en las instituciones gubernamentales (Rúa, 2013).

Por tanto, la corrupción y la falta de transparencia socavan la legitimidad, ya que ambas se relacionan con el desempeño de los procesos institucionales. La corrupción se suele definir como "el abuso del poder encomendado para beneficio privado" (Transparency International, 2020a). La corrupción política y administrativa se materializa a través de conductas como el clientelismo, el cohecho, el fraude, el desvío de recursos o, en casos extremos, la reconfiguración y captura sistemática del Estado (Garay y Salcedo, 2014). La falta de transparencia está relacionada con el incumplimiento en la rendición de cuentas por parte instituciones estatales, a través de la violación del acceso a la información o de la manipulación de esta (Ball, 2009).

La corrupción y la falta de transparencia implican que los funcionarios y organismos públicos atienden intereses distintos a los de la ciudadanía. La percepción pública de corrupción y de falta de transparencia son entonces indicadores de la evaluación de los ciudadanos sobre el desempeño del régimen político. Además, algunos estudios han demostrado que su existencia impacta fuertemente y de manera negativa la legitimidad democrática (Seligson, 2002).

Dado que la corrupción y la falta de transparencia son manifestaciones negativas del mal desempeño de los procesos políticos (e, indirectamente, de los resultados de estos procesos políticos), constituyen un motor de la política contenciosa. Siguiendo la conceptualización de Tarrow (2011) de la política contenciosa, los escándalos de corrupción pueden crear incentivos para que ciertos actores -que normalmente no poseerían recursos para actuar por sí mismos- coordinen esfuerzos con actores más influyentes y aprovechen el cambio en la opinión pública para actuar en el escenario político.

Según Tilly y Tarrow (2015), los gobiernos pueden participar en la política contenciosa al menos de tres maneras: como objetos de acciones sociales, como iniciadores de dichas demandas o como terceras partes. Estos autores sitúan la política contenciosa en la intersección 
de la contención, la acción colectiva y la política. Es decir, las demandas sociales se inician gracias a la acción coordinada entre diferentes actores, pero también van a incluir a los gobiernos como sujetos y objetos de estos reclamos, o como monitores, garantes o reguladores de la reivindicación. Para el caso de América Latina, la corrupción y la falta de transparencia promueven la acción ciudadana para realizar reclamos al gobierno, aunque en algunos casos el gobierno participa como iniciador de estas demandas (por ejemplo, cuando el gobierno comparte la indignación ciudadana ante un caso de corrupción y decide tomar medidas extraordinarias para abordar el problema).

Dentro de una democracia, los mecanismos de la política contenciosa se relacionan con la participación política convencional y no convencional. La primera de ellas corresponde a las acciones que se desenvuelven a través de un proceso electoral, que están fomentadas por el Estado y la Constitución, y que se derivan de derechos consagrado por la ley. La segunda va más allá de los mecanismos institucionales de participación y hace referencia a distintas actividades como peticiones, campañas sostenidas de reclamos, manifestaciones, creación de movimientos sociales, reuniones y declaraciones públicas. En sus versiones más extremas, la política contenciosa no convencional puede incluir el daño a la propiedad, sabotajes, huelgas legales e ilegales y boicots (Rooij y Reeskens, 2014).

El objetivo de la participación convencional y no convencional es incidir en la acción gubernamental, bien sea directamente -afectando la formación, creación o implementación de políticas públicas-, o indirectamente -influyendo en la selección de quienes diseñan esas políticas- (Brady, Scholzman y Verba, 1995). Este escrito centra su atención en las opciones de los ciudadanos para incidir en los distintos acontecimientos políticos a través del voto -para la participación política convencional-o de la protesta - para la no convencional.

Para el caso de América Latina, estudios como el de Canache y Allison (2005) muestran que los ciudadanos ajustan sus opiniones sobre sus mandatarios y el funcionamiento de las instituciones políticas en función de su percepción de la corrupción. Sin embargo, una cuestión más específica es cómo esta percepción de corrupción modifica las preferencias de los ciudadanos por los mecanismos de participación política. A partir de lo anterior, este artículo aborda la relación entre el descontento de la ciudadanía frente al desempeño de los procesos en las estructuras formales de la democracia (estimado por la percepción de corrupción y de falta de transparencia) con el uso de mecanismos de política contenciosa (medida por las 
preferencias individuales por una participación democrática como la protesta y el voto).

Estudios recientes han tratado de resolver este interrogante y han llegado a conclusiones ambiguas: para algunos autores esta relación es positiva (es decir, cuanta más corrupción y falta de transparencia, hay mayor intención de voto o protesta), mientras que para otros es negativa (cuanta más corrupción o falta de transparencia, las personas tienden a participar menos en los espacios democráticos).

Ciertos estudios han concluido que, para el caso de América Latina, la falta de satisfacción de los ciudadanos con la democracia está asociada a mayores niveles de participación y/o contención y que esta asociación está matizada por ciertos factores individuales o de contexto. Machado, Scartascini y Tommasi (2011) encuentran que, en países de América Latina que cuentan con instituciones fuertes, es más probable que los actores participen en los procesos políticos a través de escenarios institucionalizados; mientras que en aquellos países donde las instituciones son débiles, son más atractivos las protestas y otros medios no convencionales de participación.

De manera similar, Moseley (2015) estima modelos econométricos a partir de datos de encuestas de opinión en varios países de América Latina, y concluye que las instituciones de baja calidad (cuyos gobiernos tienen poca capacidad para cumplir las expectativas de los ciudadanos), aunadas a un alto involucramiento personal en temas politicos, están asociadas a una preferencia individual hacia formas más radicales de participación política, como es el caso de las protestas masivas. Gingerich (2009), por su parte, estudia el impacto de la victimización de los ciudadanos por corrupción en la protesta antigubernamental en Bolivia y concluye que ciudadanos con altos niveles de victimización en situaciones de corrupción tienden a participar más en las protestas en contra del gobierno, siendo esta asociación más fuerte cuando existe claridad sobre la afiliación politica de los victimizadores.

Por otra parte, el estudio de Bonifácio y Paulino (2015) explora la relación entre corrupción e involucramiento político en América Latina y el Caribe, enfocándose en mecanismos concretos de participación. Los autores encontraron una fuerte relación entre haber tenido experiencias de corrupción y ciertas formas de participación política (contacto con políticos y actores gubernamentales, activismo comunitario, protesta y activismo partidista). Sin embargo, los resultados no son tan claros para la participación electoral. Por lo tanto, los autores llaman la atención sobre la necesidad de estudiar las diferentes formas de participación politica y no la participación politica como un todo. 
Diversos autores han llegado a conclusiones similares para otras regiones. Por ejemplo, Kostadinova (2013) analiza en qué medida la percepción de corrupción en la élite gobernante de Europa del Este puede alentar la votación hacia los partidos de oposición y motivar a los ciudadanos a protestar contra el mal uso del cargo público. Concluye que cuanto más los ciudadanos perciban la corrupción como generalizada en su país, más probable es que se involucren en la política.

De igual forma, Inman y Andrews (2015) analizan la corrupción y la participación en Senegal, a través de un experimento diseñado para descubrir la relación entre corrupción y participación de los ciudadanos. Los autores concluyen que las percepciones de corrupción aumentan la probabilidad participar electoralmente, siendo esta asociación más elevada cuando se trata de sectores económicamente desfavorecidos. Estos mismos patrones surgen después de examinar los datos de la encuesta de Afrobarómetro. Independientemente de su edad y su origen social, los senegaleses generalmente responden a la corrupción con una mayor participación electoral.

En contraste de lo anterior, algunos estudios han concluido que la corrupción tiene un efecto nocivo sobre la participación y, por consiguiente, socava la legitimidad democrática. Así, autores como Warren $(2004,2006)$ aseveran que la corrupción rompe el vínculo entre la toma de decisiones y el poder de los pueblos para influir en las decisiones colectivas a través de la palabra y del voto, marchitando así la cultura de la democracia. De igual forma, para el caso de Colombia, Arévalo (2018) muestra que una mayor debilidad institucional afecta el apoyo a la democracia.

En respaldo de la idea anterior, Olsson (2014) agrupa datos de participación política de 33 países, y determina que la corrupción hace que los ciudadanos sientan que no tienen influencia en la política cuando las decisiones se toman de manera corrupta, lo que disminuye su propensión a participar. Igualmente, Stockemer, LaMontagne y Scruggs (2012) argumentan que a medida que la corrupción aumenta, el porcentaje de votantes que acuden a las urnas disminuye. Asimismo, Ionescu (2013) afirma que la difusión de información sobre la corrupción conduce a una disminución en la participación, independientemente del nivel de corrupción expuesto. En esta misma línea, Costas (2013) realiza un modelo para España en el periodo 1999-2007, utilizando datos sobre escándalos de corrupción y sobre las decisiones de votación, a partir del cual concluye que los niveles agregados de corrupción disminuyen la participación de los votantes. 
Siguiendo a Bonifácio y Paulino, en vez de estudiar la participación política en general, este artículo aborda dos tipos concretos: el voto y la protesta. El documento aprovecha el hecho de que en Colombia el voto no es obligatorio y las protestas no son formalmente ilegales ${ }^{1}$, lo que permite asumir que las respuestas a las preguntas de las encuestas de opinión son medidas aceptables de las preferencias individuales declaradas para estos mecanismos de participación. La sección empírica de este trabajo provee evidencia a favor de la hipótesis de que, para el caso de Colombia, el descontento de la ciudadanía con los procesos políticos - medido a partir de la percepción de corrupción y transparencia- tiene una relación positiva con la política contenciosa. A diferencia de los estudios mencionados previamente, el análisis propuesto captura en una misma variable la opción que tienen los ciudadanos de usar diferentes formas de participación democrática (votar y protestar) o una combinación de estas. Para contextualizar el problema en el caso concreto de Colombia, la siguiente sección presenta un análisis descriptivo de ciertas variables relacionadas con la corrupción y con la participación democrática en Colombia.

\section{PARTICIPACIÓN DEMOCRÁTICA Y CORRUPCIÓN EN COLOMBIA}

Esta sección describe tres aspectos del contexto colombiano que son centrales en este artículo: participación electoral, movilizaciones sociales y percepción de corrupción y de falta de transparencia.

\section{PARTICIPACIÓN ELECTORAL}

El rasgo más sobresaliente de la cultura política colombiana es el alto nivel de abstencionismo. Como lo muestra el cuadro 1, en nivel de participación electoral en las elecciones nacionales de los últimos años, tanto en las legislativas como en las presidenciales, ronda el $50 \%$ y en la mayoría de los casos es inferior a esta cifra. El nivel de abstención para el plebiscito por la paz de 2016, cuyo propósito era respaldar popularmente los acuerdos de paz con las Fuerzas Armadas Revolucionarias de Colombia (FARC), fue aún mayor, ya que solo el $38,5 \%$ de los votantes elegibles se presentaron a las urnas.

\footnotetext{
${ }^{1}$ Aunque en los últimos años se ha reabierto la discusión de cómo el Estado colombiano y los grupos al margen de la ley reprimen en la práctica las protestas y las movilizaciones, consideramos que, en el contexto de una encuesta como Latinobarómetro, los encuestados no tienen razones para ocultar sus verdaderas preferencias por diferentes mecanismos de participación política.
} 
Cuadro 1

A. Participación electoral. Elecciones presidenciales, 2006-2018

\begin{tabular}{ccccccc}
\hline 2006 & 2010 & 2010 & 2014 & 2014 & 2018 & 2018 \\
& 1 ra vuelta & 2 da vuelta & 1ra vuelta & 2 da vuelta & $\begin{array}{c}\text { 1ra vuelta } \\
2 \text { da vuelta }\end{array}$ \\
\hline $45,05 \%$ & $49,3 \%$ & $44,35 \%$ & $40,10 \%$ & $47,97 \%$ & $53,38 \%$ & $53,04 \%$ \\
\hline
\end{tabular}

B. Participación electoral. Elecciones legislativas, 2010-2018

\begin{tabular}{ccc}
\hline 2010 & 2014 & 2018 \\
\hline $44,20 \%$ & $43,58 \%$ & $48,82 \%$ \\
\hline
\end{tabular}

Nota: la participación electoral resulta de dividir el potencial electoral (personas aptas para votar) entre el total de votos.

Fuente: Registraduría Nacional del Estado Civil, elaboración propia.

La Encuesta de Cultura Política (ECP) de 2019, arroja más luces sobre este asunto, pues muestra una radiografía de las percepciones y prácticas ciudadanas alrededor de la democracia (Dane, 2019). E1 descontento con los procesos (corrupción) y los resultados (incumplimiento de las promesas políticas) del sistema político aparecen como algunas de las explicaciones más relevantes del abstencionismo, cuando se les preguntó a los encuestados por qué se abstuvieron de votar en las elecciones presidenciales de 2018. Las respuestas más comunes estuvieron relacionadas con la afirmación de que "los candidatos prometen y no cumplen", la idea de que "los políticos son corruptos", la falta de credibilidad en el proceso electoral, la falta de un candidato que represente al ciudadano, el simple desinterés y la no inscripción del documento de identidad para poder votar. Sin embargo, el abstencionismo no debe estar asociado automáticamente con la falta de apoyo al régimen democrático. De hecho, el $80,7 \%$ de los encuestados cree que es muy importante vivir en un país democrático.

\section{MOVILIZACIONES SocIALES}

Según el Centro de Investigación y Educación Popular (Cinep, 2016) las movilizaciones ciudadanas aumentaron en Colombia durante el período 2002-2013: en 2002 se registraron alrededor de 450 episodios de movilización social, mientras que en 2013 se registraron alrededor de 1.032. Si bien no existen fuentes comparables que calculen el número de protestas de los últimos años, es posible que esta cifra haya aumentado de manera sostenida durante la última década y haya alcanzado un pico durante las movilizaciones de 2019-2021. Algunas de las motivaciones más importantes de estas protestas fueron la defensa de derechos (vida, libertad, integridad personal 
y derechos económicos, laborales, políticos, sociales, culturales y étnicos), incumplimiento de políticas gubernamentales, conflictos territoriales y habitacionales, falta de infraestructura o servicios sociales y demandas ambientales.

Estas motivaciones para las protestas muestran el descontento de los ciudadanos con los resultados del régimen democrático: perciben que los gobiernos son incapaces de enfrentar los problemas económicos, sociales y de seguridad de la población (Velasco, 2015). Siguiendo a Huntington (1965), los factores estructurales también pueden ser responsables de este aumento de las movilizaciones sociales. En particular, el desarrollo social y la modernización del país se han traducido en el surgimiento y difusión de nuevas ideas, que desencadenan el inconformismo, y nuevas aspiraciones y reclamos sociales (Huntington, 1965; Archila, 2003).

A partir de estos cálculos es posible concluir que los episodios de movilización ciudadana han aumentado en Colombia durante el siglo XXI. Lo anterior está relacionado con la insatisfacción ciudadana frente al régimen democrático, pues los ciudadanos perciben una "incapacidad estatal” a la hora de enfrentar el contexto económico, social y de seguridad de la población. Estos procesos son expresados a través de reclamos simbólicos, públicos, comunales y, dependiendo del contexto, pueden llegar a producir acciones de violencia (Archila, 2003). Siguiendo a Huntington (1965), este aumento de las movilizaciones se explica, desde un enfoque más estructural, por el desarrollo social y modernización del país, que permiten el surgimiento y la difusión de nuevas ideas que a su vez desencadenan en nuevas aspiraciones, inconformismos y reclamos sociales.

\section{PERCEPCIÓN DE CORRUPCIÓN Y FALTA DE TRANSPARENCIA}

Los mecanismos como el voto y la protesta suelen ser formas de expresar el inconformismo existente debido al descontento de la ciudadanía con el desempeño de los procesos de los regímenes democráticos. Dicho descontento puede ser medido a través de indicadores como la percepción de corrupción y la falta de transparencia (Norris, 2011).

Según Garay y Salcedo (2014), en Colombia la corrupción es un fenómeno sistemático que se caracteriza por la existencia de relaciones duraderas entre diferentes agentes, que a su vez han capturado y reconfigurado al Estado. En efecto y a manera de ejemplo, en los últimos años el país ha presenciado numerosos escándalos que han estado en la intersección de la corrupción política (Caso 'Yidispolítica' 
en 2008) la corrupción administrativa (Carteles de la hemofilia y del Sida, en 2016 y 2018, respectivamente) y la corrupción privada (Caso Odebrecht, que inició en 2016) ${ }^{2}$.

Para analizar el alcance de la corrupción en el país (al margen de las dificultades para su medición) es posible revisar indicadores como el Índice de Percepción de Corrupción (Transparencia Internacional) o el indicador de Control de la Corrupción (Banco Mundial). Según el primer indicador, que muestra la percepción que tienen expertos y empresarios sobre la corrupción en Colombia, en 2019 el país ocupó el puesto 96 de 180 países en la escala de los países menos corruptos, lo que significa que el país se ubica en la mediana de la escala de corrupción, esto es, alrededor del 50\% de los países estudiados tiene niveles de corrupción más bajos, mientras que el otro $50 \%$ tiene niveles de corrupción más altos (Transparency International, 2020b).

Por otro lado, el indicador de control de corrupción, parte de los Indicadores de Gobernanza del Banco Mundial, captura en qué medida se ejerce el poder público para obtener beneficios privados, incluyendo formas de "pequeña" y "gran" corrupción, así como la captura del Estado por parte de élites e intereses privados. El indicador se construye a partir de múltiples fuentes de información, como encuestas de opinión y reportes de diferentes organizaciones y expertos. El indicador para Colombia ha oscilado alrededor de 45 en los últimos años. Este valor indica el rango que ocupa el país entre todos los países cubiertos por el indicador, ajustado a una escala de 0 a 100, en donde 0 corresponde al rango más bajo y 100 al rango más alto. Lo anterior implica que Colombia está por debajo de la mediana en materia de corrupción, lo que es evidencia a favor de que el país ha mantenido altos niveles de corrupción durante los últimos años, al menos a nivel comparativo (Kaufmann y Kraay, 2021).

A pesar de la evidencia de que Colombia podría ser calificado como un país con alto nivel de corrupción, las actitudes hacia las formas de participación política estarían asociadas con la percepción ciudadana de corrupción y falta de transparencia, pero no necesariamente con los indicadores globales de corrupción mencionados anteriormente. Por lo tanto, es necesario revisar, a partir de diferentes encuestas de opinión, en qué medida los ciudadanos perciben que Colombia es un país corrupto, lo cual es un indicador de su descontento con el funcionamiento de los procesos del sistema democrático actual.

${ }^{2}$ Para el análisis de algunas mediciones objetivas de la corrupción en Colombia, ver Ortiz y Calixto (2018) 
Según la ECP de 2019 (Dane, 2019), un alto porcentaje de colombianos consideran que el Congreso de la República, el Gobierno nacional y el Gobierno municipal son "muy corruptos" (46,3\%, $41,7 \%$ y $37,1 \%$, respectivamente). Más aún, al calificar los niveles de corrupción de las diferentes áreas del sector público en una escala de 1 a 5, más del $60 \%$ de los encuestados asigna una calificación de 4 o de 5 (en donde 5 indica que el encuestado considera que el área es "muy corrupta"). Por otro lado, el 50\% de los colombianos considera que el sector que enfrenta los casos más graves de corrupción es el sector de la salud. A partir de la encuesta también se puede concluir que los colombianos consideran que la corrupción ha aumentado (80\% de los encuestados estuvieron de acuerdo con esta afirmación en la encuesta del 2017 mientras que el 67\% estuvo de acuerdo en la encuesta del 2019).

Otra fuente relevante de información sobre la percepción ciudadana en temas de corrupción es el Barómetro Global de Corrupción 2019, realizado por Transparencia Internacional. Según los datos para Colombia, el 94\% de los encuestados consideran que la corrupción en el gobierno es un problema grave, lo que soporta la idea de que los colombianos están descontentos con el funcionamiento de los procesos en el sistema democrático (Pring y Vrushi, 2019). Más interesante aún, el $40 \%$ de los encuestados afirmaron haber recibido sobornos a cambio de votos, lo que pone un manto de duda sobre la calidad de los procesos electorales y la actitud ciudadana frente a la mecánica del sistema democrático.

\section{ANÁLISIS EMPÍRICO}

En esta sección se presenta un modelo econométrico para analizar la relación entre las preferencias individuales por las formas de participación política con la percepción individual de corrupción y falta de transparencia. El modelo se estima para el caso de Colombia a partir de la encuesta Latinobarómetro de 2015, que cuenta con cerca de 1200 respuestas de ciudadanos de este país ${ }^{3}$.

\footnotetext{
3 Aunque hay ediciones más recientes de la encuesta Latinobarómetro, en el momento de redactar este artículo, ninguna de ellas incluía preguntas relacionadas con las opiniones sobre los mecanismos de participación política que ofrecieran la posibilidad de comparar la elección de diferentes mecanismos simultáneamente.
} 


\section{CONSTRUCCIÓN DE VARIABLES Y ESTADÍSTICAS DESCRIPTIVAS}

\section{Preferencias por las formas de participación}

Las preferencias por las formas de participación política se operacionalizaron a través de la respuesta a la siguiente pregunta:"¿Qué está más cerca de su manera de pensar? ¿Cómo cree que es mejor actuar para que usted y el país avancen más?"

Los encuestados tenían cinco opciones de respuesta, a saber:

i. "Hay que votar siempre"

ii. "Hay que votar pero también protestar"

iii. "Hay que sólo protestar, no sirve votar"

iv. "No hacer nada, ni votar ni protestar"

v. "No sé qué hay que hacer"

Estas categorías capturan las preferencias por el uso de mecanismos de participación convencional (votación) y no convencional (protesta). Por otro lado, la falta de preferencia o apatía está representada por las categorías iv. y v. Las opciones de respuesta permiten inferir si los ciudadanos prefieren protestar como un sustituto (iii.) o como un complemento (ii.) a votar, lo que permite abordar de forma más rica el efecto de las percepciones de corrupción y falta de transparencia sobre las actitudes ciudadanas frente a estas formas de participación.

Un análisis preliminar de las respuestas a esta pregunta (cuadro 2) indica que la mayoría de las personas prefiere votar o votar y protestar. Además, el hecho de que sólo el 4\% de los encuestados considere que sólo sirve protestar indica que la protesta es vista como un complemento y no como un sustituto de votar.

Cuadro 2

Preferencias por los mecanismos de participación

\begin{tabular}{lcc}
\hline Opción de respuesta & Frecuencia & Porcentaje \\
\hline [1] "Hay que votar siempre” & 523 & 44,55 \\
[2] "Hay que votar pero también protestar" & 434 & 36,97 \\
[3] "Hay que sólo protestar, no sirve votar" & 47 & 4,00 \\
[4] "No hay que hacer nada, ni votar ni protestar" & 49 & 4,17 \\
[5] "No sé qué hay que hacer" & 121 & 10,31 \\
Total & 1.174 & 100,00 \\
\hline
\end{tabular}

Fuente: Latinobarómetro (2015), cálculos propios.

\section{Percepciones ciudadanas sobre el desempeño del régimen político}

Las opiniones ciudadanas sobre el desempeño del régimen político fueron operacionalizadas a través de cuatro preguntas relacionadas 
con la percepción ciudadana sobre corrupción y transparencia. Estas preguntas, junto con las opciones de respuesta, se muestran a continuación. En corchetes, el número asignado a cada respuesta en la categorización realizada para fines de manipulación estadística.

1. Conoce de corrupción: "SSabe de algún acto de corrupción en los últimos doce meses?"; "Sî" [1] o "No" [0].

2. Progreso en reducir la corrupción: "Se ha progresado en reducir la corrupción en las instituciones del Estado"; "Mucho" [4], "Algo" [3], "Poco" [2], "Nada" [1].

3. Transparencia del gobierno: "[considera que existe] Transparencia en el gobierno"; "Mucho" [4], "Algo" [3], "Poco" [2], "Nada" [1].

4. Transparencia del Estado: "[considera que existe] Transparencia en el Estado"; "Mucho" [4], "Algo"[3], "Poco"[2], "Nada" [1].

El cuadro 3 resume las frecuencias absolutas y relativas para cada categoría de las cuatro variables. Aunque la mayoría de los encuestados no conoce directamente de algún acto de corrupción (85\%), el 65\% de los encuestados considera que ha habido poco o ningún progreso en reducir la corrupción. Por otro lado, más del 70\% de los encuestados consideran que el gobierno y el Estado son poco o nada transparentes. Lo anterior va en línea con los resultados de las encuestas de opinión resumidos en la sección anterior, que constatan que la idea de que la mayoría de los colombianos considera que vive en un país con altos niveles de corrupción y baja transparencia.

Cuadro 3

Percepción de corrupción de los ciudadanos

Conocimiento de corrupción: "¿Sabe de algún acto de corrupción en los últimos doce meses?"

\begin{tabular}{lcc}
\hline Opción de respuesta & Frecuencia & Porcentaje \\
\hline "No" [0] & 989 & 84,39 \\
"Sí" [1] & 183 & 15,61 \\
Total & 1,172 & 100,00 \\
\hline
\end{tabular}

Progreso en reducir la corrupción: "Se ha progresado en reducir la corrupción en las instituciones del Estado";

\begin{tabular}{lll}
\hline Opción de respuesta & Frecuencia & Porcentaje \\
\hline "Nada" [1] & 316 & 27,19 \\
"Poco"[2] & 445 & 38,30 \\
"Algo"[3] & 294 & 25,30 \\
"Mucho" [4] & 107 & 9,21 \\
Total & 1,162 & 100,00 \\
\hline
\end{tabular}


Transparencia del gobierno: "[considera que existe] Transparencia en el gobierno"

\begin{tabular}{lll}
\hline Opción de respuesta & Frecuencia & Porcentaje \\
\hline "Nada" [1] & 434 & 36,81 \\
"Poco" [2] & 465 & 39,44 \\
"Algo" [3] & 225 & 19,08 \\
"Mucho" [4] & 55 & 4,66 \\
Total & 1,179 & 100,00 \\
\hline
\end{tabular}

Transparencia del Estado: "[considera que existe] Transparencia en el Estado"

\begin{tabular}{lll}
\hline Opción de respuesta & Frecuencia & Porcentaje \\
\hline "Nada" [1] & 425 & 36,48 \\
"Poco" [2] & 477 & 40,94 \\
"Algo" [3] & 213 & 18,28 \\
"Mucho" [4] & 50 & 4,29 \\
Total & 1,165 & 100,00 \\
\hline
\end{tabular}

Fuente: Latinobarómetro (2015), cálculos propios.

\section{Variables de control}

En la especificación econométrica se incluyeron algunas variables de control, porque su inclusión permite obtener estimadores menos sesgados de la asociación de la percepción de corrupción y de transparencia con las preferencias por el tipo de participación política. En efecto, las variables escogidas pueden estar correlacionadas tanto con las preferencias por las formas de participación política como con las percepciones de corrupción y transparencia.

1. Características sociales. Lake y Huckfeldt (1998), Leighley (1995) y Nie, Powell y Prewitt (1969) encuentran que ciertas características individuales están asociadas a las preferencias por distintas formas de participación política. Además, estas variables pueden estar asociadas a la percepción de corrupción y de falta de transparencia. A partir de lo anterior, se incluyeron los siguientes controles: (i) El nivel de educación de los encuestados, tratado como una variable continua que puede asumir 17 valores, desde la falta de educación formal hasta la educación de posgrado. (ii) La edad, medida en años. (iii) El género, 1 para hombres y 0 para mujeres. (iv) La religiosidad, codificada en una escala de 4 puntos, cuyo menor valor simboliza la falta de devoción y el mayor significa una mayor práctica o devoción.

2. Ideología política. Las inclinaciones políticas de las personas pueden estar asociadas a su preferencia por ciertas formas de participación. Además, las afiliaciones políticas de las autoridades 
incumbentes pueden matizar la percepción de corrupción por parte del ciudadano. Por lo tanto, en la estimación empírica se incluyó la variable de ideología, que contiene 11 categorías que representan la identificación del entrevistado como de izquierda (cuando se acerca más a cero) o de derecha (cuando se acerca más a 10).

3. Condiciones económicas. Estudios del comportamiento individual han encontrado que factores económicos son predictores robustos de la participación en distintas democracias (Wolfinger y Rosenstone, 1980; Powell, 1982; Brady, Verba y Schlozman, 1995 y Norris, 2002). Además, estas condiciones pueden determinar el nivel de información y criterio de los ciudananos para evaluar el funcionamiento del sistema político, por lo que están asociadas también a las percepciones de corrupción y falta de transparencia. El proxy del nivel de ingreso fue el ingreso subjetivo, variable categórica que indica si el encuestado considera que su ingreso es suficiente para cubrir sus necesidades.

Las estadísticas descriptivas de las variables de control se resumen en el cuadro 4.

\section{ESTIMACIÓN DEL MODELO}

Para responder la pregunta de investigación implementamos un modelo logístico multinomial, que permite analizar la elección individual cuando existen más de dos categorías que no tienen un orden natural, como es el caso de las preferencias por las formas de participación política. En el modelo logístico multinomial se estiman en realidad modelos, donde $K$ es el número de niveles o categorías de la variable dependiente. La categoría que no se estima explícitamente se convierte en el grupo de referencia, lo cual implica que las estimaciones de los parámetros son relativas a dicho grupo. Para este caso concreto, se escogió la categoría "Hay que votar siempre" como la base de comparación.

En este modelo se parte de $n$ observaciones independientes que están localizadas en las $K$ categorías. La distribución de probabilidad del número de observaciones de dichas categorías sigue una distribución logística multinomial, que modela la probabilidad de cada una de las posibles maneras en que las $n$ observaciones pueden repartirse entre las $K$ categorías.

Al tomar una categoría $K$ como respuesta base, el modelo logit que se define con respecto a ella es el siguiente: 
Cuadro 4

Estadísticas descriptivas de las variables de control

\begin{tabular}{|c|c|c|c|c|c|}
\hline Variable (continua) & $\begin{array}{c}\text { Observaciones } \\
\text { válidas }\end{array}$ & Media & $\begin{array}{c}\text { Desviación } \\
\text { estándar }\end{array}$ & Mínimo & Máximo \\
\hline Edad (años) & 1.200 & 40,5 & 16,4 & 18 & 94 \\
\hline Educación (años) & 1.200 & 12,5 & 3,75 & 1 & 17 \\
\hline $\begin{array}{l}\text { Ideología política } \\
\text { o: Izquierda; } 10: \text { Derecha }\end{array}$ & 1.023 & 6,2 & 2,78 & 0 & 10 \\
\hline Variable (categórica) & $\begin{array}{c}\text { Observaciones } \\
\text { válidas }\end{array}$ & Frecuencia & Porcentaje & & \\
\hline Género & 1.200 & & & & \\
\hline Masculino & & 573 & 47,75 & & \\
\hline Femenino & & 627 & 52,25 & & \\
\hline Religiosidad & 1.116 & & & & \\
\hline [1] Nada religioso & & 85 & 7,62 & & \\
\hline$[2]$ & & 391 & 35,04 & & \\
\hline$[3]$ & & 495 & 44,35 & & \\
\hline [4] Muy religioso & & 145 & 12,99 & & \\
\hline $\begin{array}{l}\text { Ingresos subjetivos } \\
\text { "Los ingresos son suficientes } \\
\text { para satisfacer las necesi- } \\
\text { dades" }\end{array}$ & 1.179 & & & & \\
\hline [1] Para nada & & 176 & 14,93 & & \\
\hline$[2]$ & & 455 & 38,59 & & \\
\hline$[3]$ & & 432 & 36,64 & & \\
\hline [4] Es más que suficiente & & 116 & 9,84 & & \\
\hline
\end{tabular}

Fuente: Latinobarómetro (2015), cálculos propios.

$\log =\left(\frac{\pi_{k}}{\pi_{k}}\right)=\beta_{0 k}+\beta_{i k} X_{i}$

donde:

$k=\{1, \ldots K-1\}$, es decir, todas categorías asociadas a las preferencias por formas de participación política, excluyendo la primera respuesta ("Hay que votar siempre").

$\left\{\pi_{1}, \ldots \pi_{k}\right\}$ representa las probabilidades asociadas a las distintas respuestas. Como la respuesta es única, se satisface que $\Sigma_{k} \pi_{k}=1$.

$X_{i}$ se refiere a la matriz de variables independientes, incluyendo las variables categóricas de interés (percepciones de corrupción y falta de transparencia) y los controles. Como las variables de interés son también categóricas, en modelo se incluyeron todas las opciones de respuesta menos una.

$\beta_{i k}$ es el vector de parámetros estimados asociados a $X_{i}$, que recoge el efecto marginal de cada variable sobre $\log =\left(\frac{\pi_{k}}{\pi_{k}}\right)$.

Como el modelo tiene $K-1$ ecuaciones con sus respectivos parámetros, los efectos de las variables independientes sobre $\log =\left(\frac{\pi_{k}}{\pi_{\xi}}\right)$ varían según la categoría analizada $(k)$. Para facilitar la interpretación de los 
resultados, luego de la estimación de los parámetros se procede a calcular los efectos marginales, es decir, el efecto que tiene mover alguna variable contenida en $X$ sobre la probabilidad de preferir la categoría $k$ respecto a la categoría base ("Hay que votar siempre").

Se hicieron 4 estimaciones, una por cada variable independientes que mide la percepción ciudadana de corrupción y de falta de transparencia ("Conoce de corrupción", "Progreso en reducir la corrupción", “Transparencia del gobierno", “Transparencia del Estado”). Es decir, cada regresión solo incluye una de las variables explicativas, además de los controles, lo que evita los problemas de multicolinealidad asociados a incluir variables explicativas altamente correlacionadas. Todas las regresiones incluyen al menos 887 observaciones y un máximo de 900 .

\section{RESUlTADOS}

El cuadro 5 presenta los resultados de los coeficientes de cada modelo estimado.

El modelo 1 indica que quienes conocen un caso de corrupción (con respecto a quienes no conocen ningún caso) se inclinan más a votar y protestar (categoría 2) que solo a votar (categoría 1). El modelo 2 indica que quienes consideran que el gobierno ha avanzado mucho en reducir la corrupción (con respecto a quienes consideran que no se ha avanzado nada) están menos inclinadas a votar y protestar (categoría 2) que solo a votar (categoría 1). Ese mismo patrón se observa en los modelos 3 y 4: quienes consideran que el gobierno es altamente transparente se inclinan menos a votar y protestar que solo a votar.

Los resultados de la opción "solo protestar" tienen un patrón menos claro. En general, si las personas consideran que el gobierno y el Estado son poco, algo o muy transparentes (con respecto a quienes consideran que no son nada transparentes), están menos inclinadas a escoger "solo protestar". Y si consideran que el gobierno hace poco, algo o mucho para disminuir la corrupción (con respecto a quienes consideran que el gobierno no hace nada), también están menos inclinados a escoger la opción de "solo protestar". Además, si las personas conocen algún caso de corrupción, están más inclinadas a decantarse por esta opción. No obstante, la magnitud de los coeficientes para cada categoría no muestra un comportamiento monotónico, esto es, el efecto sobre la variable explicada (escoger "sólo protestar") de ascender o descender en la escala de las variables explicativas no tiene una sola dirección.

Para facilitar la interpretación de los resultados, los cuadros 6A a $6 \mathrm{D}$ y las gráficas $1 \mathrm{~A}$ a $1 \mathrm{D}$ muestran los cambios en las probabilidades de que un ciudadano haya escogido cada categoría de la 
Cuadro 5

Resultados econométricos

\begin{tabular}{|c|c|c|c|c|c|}
\hline \multirow[t]{2}{*}{ Modelo } & \multirow[t]{2}{*}{ Variable independiente } & \multicolumn{4}{|c|}{ Variable dependiente: Participación política } \\
\hline & & $\begin{array}{l}\text { Votar y } \\
\text { protestar }\end{array}$ & $\begin{array}{c}\text { Solo } \\
\text { protestar }\end{array}$ & $\begin{array}{c}\text { No hacer } \\
\text { nada }\end{array}$ & $\begin{array}{l}\text { No sabe } \\
\text { qué hacer }\end{array}$ \\
\hline \multirow[t]{2}{*}{1} & $\begin{array}{l}\text { Conoce de corrupción } \\
\text { Base: }[0] \text { No }\end{array}$ & & & & \\
\hline & [1] Sí & $\begin{array}{c}0,37732^{*} \\
{[0,26]}\end{array}$ & $\begin{array}{c}0,71200 \\
{[0,48]}\end{array}$ & $\begin{array}{l}-0,49092 \\
{[0,458]}\end{array}$ & $\begin{array}{c}-0,24665 \\
{[0,388]}\end{array}$ \\
\hline \multirow[t]{4}{*}{2} & $\begin{array}{l}\text { Progreso en reducir la corrupción } \\
\text { Base: [1] Nada }\end{array}$ & & & & \\
\hline & {$[2]$ Poco } & $\begin{array}{l}-0,30724 \\
{[0,139]}\end{array}$ & $\begin{array}{c}-1,24944^{* *} \\
{[0,336]}\end{array}$ & $\begin{array}{c}-0,62893 \\
{[0,371]}\end{array}$ & $\begin{array}{c}-0,20369 \\
{[0,325]}\end{array}$ \\
\hline & [3] Algo & $\begin{array}{l}-0,21761 \\
{[0,199]}\end{array}$ & $\begin{array}{l}-1,46096^{* *} \\
{[0,703]}\end{array}$ & $\begin{array}{c}-0,18038 \\
{[0,675]}\end{array}$ & $\begin{array}{c}-0,55393 \\
{[0,362]}\end{array}$ \\
\hline & [4] Mucho & $\begin{array}{c}-0,88890^{* * * *} \\
{[0,332]}\end{array}$ & $\begin{array}{c}-0,68119 \\
{[0,731]} \\
\end{array}$ & $\begin{array}{l}0,30500 \\
{[0,519]}\end{array}$ & $\begin{array}{c}-0,75100 \\
{[0,390]}\end{array}$ \\
\hline \multirow[t]{4}{*}{3} & $\begin{array}{l}\text { Transparencia del gobierno } \\
\text { Base: [1] Nada }\end{array}$ & & & & \\
\hline & [2] Poco & $\begin{array}{c}-0,28081 \\
{[0,166]}\end{array}$ & $\begin{array}{c}-1,66670^{* * *} \\
{[0,466]}\end{array}$ & $\begin{array}{c}-1,33963^{* * * *} \\
{[0,348]}\end{array}$ & $\begin{array}{c}-0,29979 \\
{[0,204]}\end{array}$ \\
\hline & [3] Algo & $\begin{array}{c}-0,56943^{* * *} \\
{[0,201]}\end{array}$ & $\begin{array}{l}-1,50147^{* *} \\
{[0,805]}\end{array}$ & $\begin{array}{l}-0,86946 \\
{[0,464]}\end{array}$ & $\begin{array}{c}-1,29337^{\text {**** }} \\
{[0,417]}\end{array}$ \\
\hline & [4] Mucho & $\begin{array}{c}-0,92698^{* *} \\
{[0,394]}\end{array}$ & $\begin{array}{l}-1,57502 \\
{[0,955]}\end{array}$ & $\begin{array}{c}-0,36748 \\
{[0,978]} \\
\end{array}$ & $\begin{array}{c}-0,83823 \\
{[0,316]}\end{array}$ \\
\hline \multirow[t]{4}{*}{4} & $\begin{array}{l}\text { Transparencia del Estado } \\
\text { Base: [1] Nada }\end{array}$ & & & & \\
\hline & [2] Poco & $\begin{array}{l}-0,28956 \\
{[0,208]}\end{array}$ & $\begin{array}{c}-1,94789^{* * * *} \\
{[0,701]}\end{array}$ & $\begin{array}{c}-0,89706^{* *} \\
{[0,401]}\end{array}$ & $\begin{array}{c}-0,13368 \\
{[0,245]}\end{array}$ \\
\hline & [3] Algo & $\begin{array}{c}-0,23497 \\
{[0,237]}\end{array}$ & $\begin{array}{c}-1,89257^{\text {*** }} \\
{[0,967]}\end{array}$ & $\begin{array}{c}-0,92109 \\
{[0,596]}\end{array}$ & $\begin{array}{c}-1,20356^{* * *} \\
{[0,505]}\end{array}$ \\
\hline & [4] Mucho & $\begin{array}{c}-0,62222 \\
{[0,357]} \\
\end{array}$ & $\begin{array}{c}-0,35547 \\
{[0,754]} \\
\end{array}$ & $\begin{array}{l}0,31108 \\
{[1,052]} \\
\end{array}$ & $\begin{array}{c}-0,08010 \\
{[0,327]}\end{array}$ \\
\hline
\end{tabular}

Nota: *p<0,10; ${ }^{* *} \mathrm{p}<0,05 ;{ }^{* * *} \mathrm{p}<0,01$. Test de dos colas. Coeficientes para regresiones de logit multinomial. Cada coeficiente es el resultado de una regresión de la variable dependiente y de la variable independiente correspondiente (sólo una para cada regresión), además de las variables de control. Entre corchetes, errores estándar robustos a la heterocedasticidad y agrupados por ciudad.

variable dependiente para diferentes categorías de la variable explicativa. Lo anterior permite observar cómo, en promedio, crece o decrece la probabilidad de elección de cada alternativa de la variable explicada para cada categoría de la variable independiente de interés, manteniendo las variables de control en sus valores individuales originales. Por ejemplo, el primer gráfico de la gráfica 1A muestra la probabilidad de que el encuestado afirme que es mejor votar frente a las otras alternativas, para cada posible respuesta a la pregunta de si conoce algún caso de corrupción, manteniendo las variables de control en sus valores originales ${ }^{4}$.

4 Para calcular los efectos marginales usamos la aproximación del efecto marginal promedio, es decir, evaluamos las variables de control en sus valores originales. 
Como se puede observar, a pesar de que no todos los resultados son estadísticamente significativos para cada caso, la mayoría de ellos presenta un patrón de monotonicidad en la dirección esperada. Para las cuatro gráficas se presentan los resultados marginales de la variable dependiente con cada una de las variables independientes.

\section{Conocer de corrupción}

$\mathrm{Al}$ evaluar el efecto sobre la variable dependiente de la variable "Conoce de Corrupción” (gráfica 1A), se encuentra que, en general, si un ciudadano conoce hechos de corrupción es más probable que escoja "Votar y protestar" o "Sólo protestar".

\section{Gráfica $1 \mathrm{~A}$}

Probabilidades pronosticadas de las categorías de cada variable dependiente Variable independiente: Conocimiento de casos de corrupción
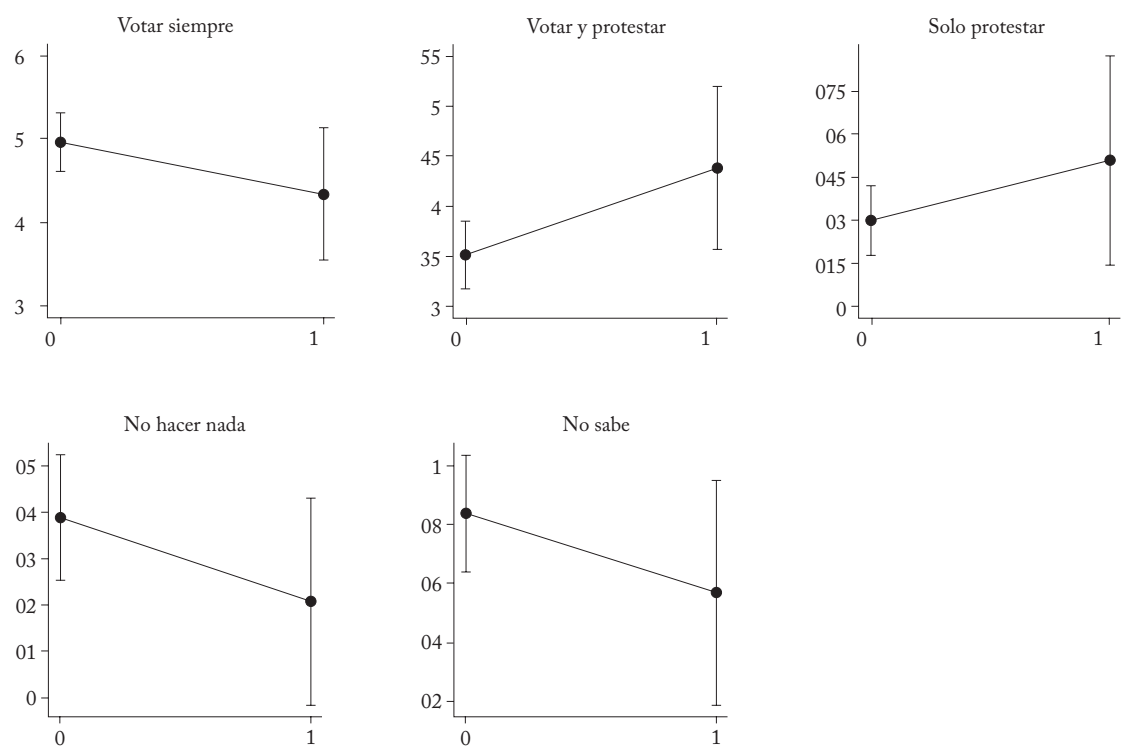

Nota: [0] No conoce, [1]: Conoce. Cálculos basados en la aproximación de efectos marginales promedio. Errores estándar del método delta entre paréntesis. ${ }^{* * *} \mathrm{p}<0,01,{ }^{* *} \mathrm{p}<0,05,{ }^{*} \mathrm{p}<0,1$.

En efecto, como muestra el cuadro 6A, si el encuestado respondió que sí conoce hechos de corrupción, la probabilidad de que escoja "Votar y protestar" aumenta 8,7 puntos porcentuales en promedio, y la de escoger "Sólo protestar". 2 puntos porcentuales. La magnitud del efecto de conocer de corrupción es mucho mayor sobre la elección de "Votar y protestar" (y es estadísticamente significativa al 10\% de nivel 
de significancia; $\mathrm{p}=0,092)$ que sobre la opción "Solo protestar", de lo que se puede concluir que, en general, los ciudadanos ven la protesta como un complemento a la acción de votar y no como un sustituto.

Cuadro 6A

Cambios previstos en las probabilidades de cada variable dependiente Variable independiente: conocimiento de casos de corrupción

Cambio en la probabilidad de elegir una de las opciones enumeradas si el encuestado conoce casos de corrupción Base: [0] No conoce casos de corrupción

\begin{tabular}{lc}
\hline $\begin{array}{l}\text { [1] "Hay que votar } \\
\text { siempre" }\end{array}$ & $\begin{array}{c}-0,0622 \\
(0,057)\end{array}$ \\
\hline [2] "Hay que votar & $0,0868^{*}$ \\
pero también protes- & $(0,052)$ \\
tar" & 0,0208 \\
\hline$[3]$ "Hay que sólo & $(0,015)$ \\
protestar, no sirve & $-0,0182$ \\
votar" & $(0,01)$ \\
\hline [4] "No hay que hacer & \\
nada, ni votar ni pro- & $-0,0272$ \\
testar" & $(0,021)$ \\
\hline [5] "No sé qué hay & 893 \\
que hacer" & \\
\hline Observaciones &
\end{tabular}

Nota: cálculos basados en la aproximación de efectos marginales promedio. Errores estándar del método delta entre paréntesis. ${ }^{* * *} \mathrm{p}<0,01,{ }^{* *} \mathrm{p}<0,05,{ }^{*} \mathrm{p}<0,1$.

\section{Percepción sobre el progreso en reducir la corrupción}

El análisis con la variable independiente "Progreso en Reducir la Corrupción”, arroja un patrón similar: si un ciudadano considera que no ha habido progreso (opción 1), es menos probable que escoja "Votar Siempre" y es más probable que escoja la opción de "Votar y Protestar". Si un ciudadano considera que no se ha avanzado nada en reducir la corrupción, disminuye en 17 puntos porcentuales la probabilidad de que escoja "Votar siempre", al tiempo que aumenta en 16 puntos porcentuales la probabilidad de que escoja "Votar y protestar", respecto a las respectivas probabilidades estimadas si el ciudadano considerara que se ha avanzado mucho en reducir la corrupción. La magnitud de estos efectos es considerable y estadísticamente significativa ( $\mathrm{p}=0,005$ y $\mathrm{p}=0,006$, respectivamente). Los resultados para la categoría de "Solo Protestar" no tienen un patrón definido y la magnitud de los efectos en la probabilidad de escoger esta opción son muy inferiores al de la opción "Votar y protestar", lo que es evidencia a favor de la idea de que los ciudadanos, al percibir que no se ha avanzado en reducir la 
corrupción, ven favorable la protesta como un complemento al voto, pero no como un sustituto.

Cuadro 6B

Cambios previstos en las probabilidades de cada variable dependiente Variable independiente: Percepción del progreso en reducir la corrupción

\begin{tabular}{|c|c|c|c|}
\hline & \multicolumn{3}{|c|}{$\begin{array}{l}\text { Cambio en la probabilidad de elegir una de las opciones } \\
\text { enumeradas si el encuestado conoce casos de corrupción } \\
\text { Línea base: [1] Nada }\end{array}$} \\
\hline & [2] Poco & [3] Algo & [4] Mucho \\
\hline [1] "Hay que votar siempre" & $0,0852^{* * * *}$ & $0,0773^{*}$ & $0,170^{* * * *}$ \\
\hline & $(0,0327)$ & $(0,0454)$ & $(0,0602)$ \\
\hline [2] "Hay que votar pero & $-0,0379$ & $-0,0112$ & $-0,161^{* * * *}$ \\
\hline también protestar" & $(0,0278)$ & $(0,0427)$ & $(0,0579)$ \\
\hline $\begin{array}{l}\text { [3] "Hay que sólo protestar, } \\
\text { no sirve votar" }\end{array}$ & $\begin{array}{l}-0,0363^{* * * *} \\
(0,01118)\end{array}$ & $\begin{array}{l}-0,0408^{* * * *} \\
(0,0128)\end{array}$ & $\begin{array}{l}-0,0143 \\
(0,0294)\end{array}$ \\
\hline $\begin{array}{l}\text { [4] "No hay que hacer nada, } \\
\text { ni votar ni protestar" }\end{array}$ & $\begin{array}{l}-0,0112 \\
(0,0105)\end{array}$ & $\begin{array}{l}0,00103 \\
(0,021)\end{array}$ & $\begin{array}{c}0,0323 \\
(0,0291)\end{array}$ \\
\hline $\begin{array}{l}\text { [5] "No sé qué hay que } \\
\text { hacer" }\end{array}$ & $\begin{array}{l}0,000132 \\
(0,0227)\end{array}$ & $\begin{array}{l}-0,0263 \\
(0,0261)\end{array}$ & $\begin{array}{l}-0,0274 \\
(0,0261)\end{array}$ \\
\hline Observaciones & 887 & 887 & 887 \\
\hline
\end{tabular}

Nota: Cálculos basados en la aproximación de efectos marginales promedio. Errores estándar del método delta entre paréntesis. ${ }^{* * *} \mathrm{p}<0,01,{ }^{* *} \mathrm{p}<0,05,{ }^{*} \mathrm{p}<0,1$.

\section{Gráfica 1B}

Probabilidades pronosticadas de las categorías de cada variable dependiente Variable independiente: Percepción del progreso en reducir la corrupción
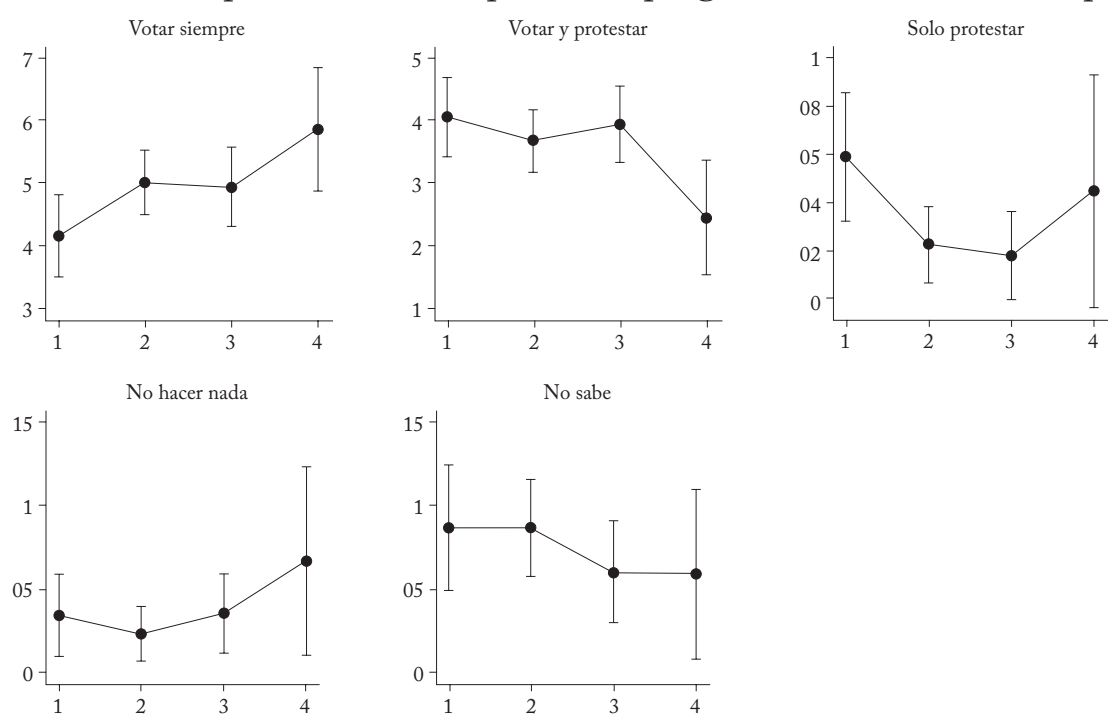

Nota: [1] Nada, [2] Poco, [3] Algo, [4] Mucho. Cálculos basados en la aproximación de efectos marginales promedio. Errores estándar del método delta entre paréntesis. ${ }^{* * *} \mathrm{p}<0,01,{ }^{* * *} \mathrm{p}<0,05,{ }^{*} \mathrm{p}<0,1$. 


\section{Percepción de la transparencia del gobierno}

Al revisar los resultados de la variable independiente "Transparencia del Gobierno" se confirma el patrón anterior: en la medida en que los ciudadanos consideren que el gobierno es poco transparente, van a estar más inclinados a votar y protestar que a solo votar. En efecto, respecto a una persona que considera que el gobierno es "muy transparente", la probabilidad de que una persona que considera que el gobierno no es nada transparente escoja "Votar siempre" disminuye en 20 puntos porcentuales y la de que escoja "Votar y protestar" aumenta en 14 puntos porcentuales, siendo estos resultados estadísticamente significativos $(\mathrm{p}=0,006$ y $\mathrm{p}=0,052$, respectivamente) Por otro lado, aunque la probabilidad de escoger "Solo protestar" aumenta si la persona considera que el gobierno no es nada transparente (respecto a considerar que el gobierno es poco, algo y muy transparente) la magnitud de este efecto es de entre 4 y 5 puntos porcentuales.

Cuadro 6C

Cambios previstos en las probabilidades de cada variable dependiente Variable independiente: Percepción de transparencia del gobierno

\begin{tabular}{lccc}
\hline & \multicolumn{3}{c}{$\begin{array}{c}\text { Cambio en la probabilidad de elegir } \\
\text { una de las opciones enumeradas si el }\end{array}$} \\
& \multicolumn{3}{c}{$\begin{array}{c}\text { Linea base: [1] Nada } \\
\text { encuestado conoce casos de corrupción }\end{array}$} \\
\cline { 2 - 4 } & {$[2]$ Poco } & {$[3]$ Algo } & {$[4]$ Mucho } \\
\hline [1] "Hay que votar siempre” & $0,0977^{* * *}$ & $0,174^{* * *}$ & $0,208^{* * *}$ \\
\cline { 2 - 4 } & $(0,0358)$ & $(0,045)$ & $(0,0698)$ \\
\hline [2] "Hay que votar pero también pro- & $-0,0143$ & $-0,0608$ & $-0,145^{*}$ \\
\cline { 2 - 4 } testar" & $(0,0319)$ & $(0,04)$ & $(0,0746)$ \\
\hline [3] "Hay que sólo protestar, no sirve & $-0,0455^{* * * *}$ & $-0,0398^{* *}$ & $-0,0401$ \\
\cline { 2 - 4 } votar" & $(0,01)$ & $(0,0154)$ & $(0,0244)$ \\
\hline [4] "No hay que hacer nada, ni votar ni & $-0,0326^{* * *}$ & $-0,0174$ & 0,00626 \\
\cline { 2 - 4 } protestar" & $(0,0116)$ & $(0,01712)$ & $(0,0474)$ \\
\hline [5] "No sé qué hay que hacer" & $-0,00529$ & $-0,0559^{* *}$ & $-0,0297$ \\
\cline { 2 - 4 } & $(0,0153)$ & $(0,0234)$ & $(0,0204)$ \\
\hline Observaciones & 900 & 900 & 900 \\
\hline
\end{tabular}

Nota: cálculos basados en la aproximación de efectos marginales promedio. Errores estándar del método delta entre paréntesis. ${ }^{* * * *} \mathrm{p}<0,01,{ }^{* * *} \mathrm{p}<0,05,{ }^{*} \mathrm{p}<0,1$.

\section{Percepción de la transparencia del estado}

E1 comportamiento del efecto de la variable "Transparencia del Estado" sobre la variable explicada es coherente con lo encontrado para la variable “Transparencia del Gobierno”, pero con magnitudes más 
bajas y un comportamiento levemente no-monotónico. Respecto a las personas que consideran que el Estado no es nada transparente, la probabilidad de que una persona que considere que el Estado es muy transparente escoja la opción de "votar y protestar" disminuye en 12 puntos porcentuales $(\mathrm{p}=0,051)$.

Gráfica $1 \mathrm{C}$

Probabilidades pronosticadas de las categorías de cada variable dependiente Variable independiente: Percepción de transparencia del gobierno
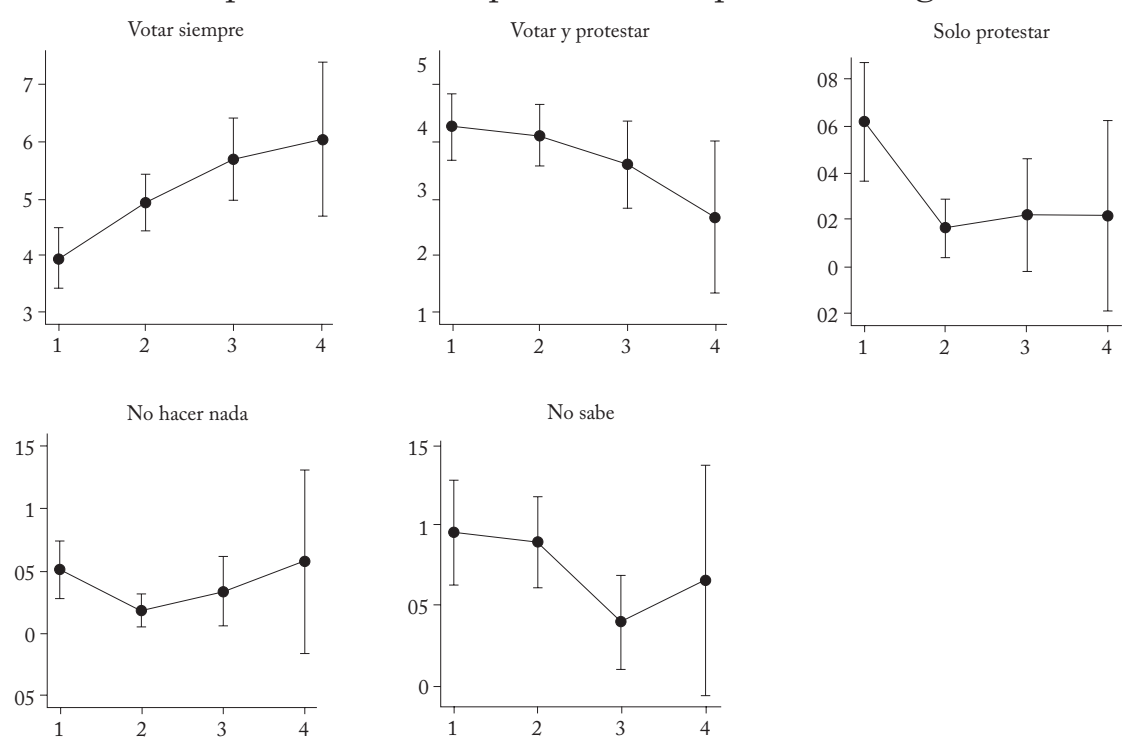

Nota: [1] Nada, [2] Poco, [3] Algo, [4] Mucho. Cálculos basados en la aproximación de efectos marginales promedio. Errores estándar del método delta entre paréntesis. ${ }^{* * *} \mathrm{p}<0,01,{ }^{* *} \mathrm{p}<0,05,{ }^{*} \mathrm{p}<0,1$.

\section{Otros resultados}

En esta subsección, se revisa brevemente algunos de los resultados de estimación relacionados con las variables control. En primer lugar, se encontró una relación estadísticamente significativa y entre la ideología y las preferencias por los mecanismos de participación política: las personas con mayor propensión a ubicarse más a la derecha en el espectro político prefieren votar que votar y protestar, mientras que aquellos que se sitúan más hacia la izquierda tienden a preferir votar y protestar que solo votar. En segundo lugar, se encontró que los encuestados con niveles más bajos de educación prefieren votar y protestar que solo votar. Por su parte, aunque el nivel de ingreso no siempre tiene un efecto estadísticamente significativo, la preferencia por votar es constante a través de todos los niveles de ingreso. 
Cuadro 6D

Cambios previstos en las probabilidades de cada variable dependiente Variable independiente: Percepción de transparencia del Estado

\begin{tabular}{|c|c|c|c|}
\hline & \multicolumn{3}{|c|}{$\begin{array}{c}\text { Cambio en la probabilidad de elegir } \\
\text { una de las opciones enumeradas si el } \\
\text { encuestado conoce casos de corrupción } \\
\text { Línea base: [1] Nada }\end{array}$} \\
\hline & [2] Poco & [3] Algo & [4] Mucho \\
\hline \multirow[t]{2}{*}{ [1] "Hay que votar siempre" } & $0,0909^{* *}$ & $0,112^{* *}$ & 0,0926 \\
\hline & $(0,045)$ & $(0,0529)$ & $(0,0731)$ \\
\hline \multirow{2}{*}{$\begin{array}{l}\text { [2] "Hay que votar pero también } \\
\text { protestar" }\end{array}$} & $-0,0244$ & 0,0127 & $-0,127^{*}$ \\
\hline & $(0,0403)$ & $(0,0487)$ & $(0,0648)$ \\
\hline \multirow{2}{*}{$\begin{array}{l}\text { [3] "Hay que sólo protestar, no sirve } \\
\text { votar" }\end{array}$} & $-0,0535^{* * * *}$ & $-0,0522^{* * *}$ & $-0,00816$ \\
\hline & $(0,0131)$ & $(0,0158)$ & $(0,0401)$ \\
\hline \multirow{2}{*}{$\begin{array}{l}\text { [4] "No hay que hacer nada, ni votar ni } \\
\text { protestar" }\end{array}$} & $-0,0208$ & $-0,0202$ & 0,0299 \\
\hline & $(0,0134)$ & $(0,0177)$ & $(0,0634)$ \\
\hline \multirow[t]{2}{*}{ [5] "No sé qué hay que hacer" } & 0,00789 & $-0,0527 * *$ & 0,0124 \\
\hline & $(0,0167)$ & $(0,0263)$ & $(0,0275)$ \\
\hline Observaciones & 892 & 892 & 892 \\
\hline
\end{tabular}

Nota: cálculos basados en la aproximación de efectos marginales promedio. Errores estándar del método delta entre paréntesis. ${ }^{* * * *} \mathrm{p}<0,01,{ }^{* * *} \mathrm{p}<0,05,{ }^{*} \mathrm{p}<0,1$.

\section{Gráfica 1D}

Probabilidades pronosticadas de las categorías de cada variable dependiente Variable independiente: Percepción de transparencia del Estado
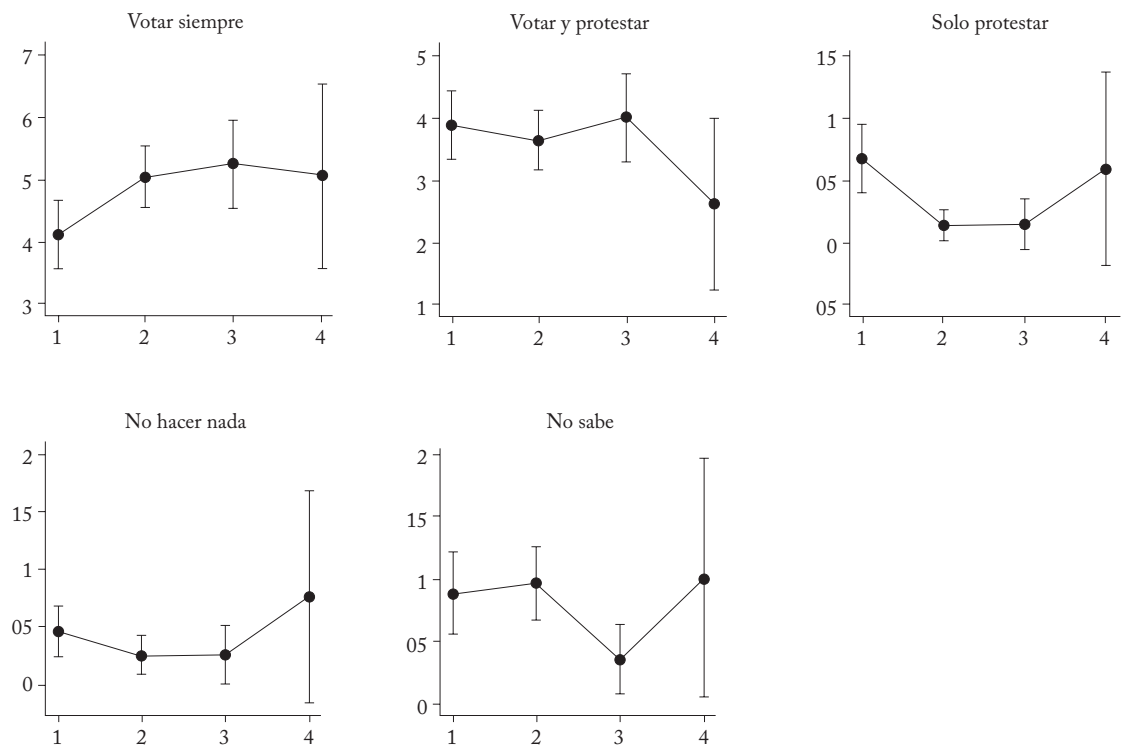

Nota: [1] Nada, [2] Poco, [3] Algo, [4] Mucho. Cálculos basados en la aproximación de efectos marginales promedio. Errores estándar del método delta entre paréntesis. ${ }^{* * * *} \mathrm{p}<0,01,{ }^{* * *} \mathrm{p}<0,05,{ }^{*} \mathrm{p}<0,1$. 
Aunque los resultados presentados en esta sección empírica no son evidencia a favor de una relación de causalidad entre la percepción de corrupción y transparencia y las preferencias por los mecanismos de participación política, pero revelan asociaciones interesantes y coherentes con el marco analítico expuesto en la sección II.

\section{DISCUSIÓN}

\section{APoyo a la Democracia a PESAR DE TODO}

La sección anterior proporciona evidencia sobre la relación existente entre la política contenciosa (medida a través de las preferencias por las formas de participación del voto y la protesta) con el descontento de la ciudadanía frente al desempeño de los procesos (medido por la percepción de corrupción y falta de transparencia del gobierno y del Estado). Los resultados muestran que existe una relación positiva entre estos dos aspectos: ante una mayor percepción de corrupción, los colombianos van a preferir votar y protestar, mientras que si se considera que ha habido progreso en reducir la corrupción o que existen altos niveles de transparencia, van a preferir votar sin protestar.

Si los ciudadanos perciben mayores niveles de corrupción tienden a expresar mayor preferencia por mecanismos de participación como la protesta, sin que esto afecte el uso de las urnas como mecanismo de expresión. Es decir, la protesta es vista como un complemento, no como un sustituto, de los mecanismos electorales. Muestra de ello es que una muy baja proporción de los ciudadanos encuestados están dispuestos a renunciar al voto. Este respeto que demuestran tener los ciudadanos hacia el sufragio -forma de expresión y componente esencial de la democracia (Nohlen, 2004, pág. 141)- podría indicar la existencia de un arraigo del sistema democrático en el país.

Estos hallazgos contribuyen a la discusión en Colombia acerca del establecimiento y estabilización de la democracia. Los resultados sugieren que existe una amplia aceptación de las instituciones y prácticas democráticas, por lo que ningún grupo social significativo está dispuesto a trastornar este orden político y sustituirlo por otro (Schedler, 1997). En otras palabras, la democracia, en el sentido de mecanismos electorales, "is the only game in town" (Linz y Stepan, 1996, p. 5)

Antes de la constitución de 1991, algunos autores consideraban que Colombia había entrado en un proceso de retroceso democrático (Peeler, 1991), debido a la ruptura democrática de los años cincuenta y a la posterior puesta en marcha del Frente Nacional. No obstante, 
el proceso constituyente de 1991 implicó un nuevo impulso a la consolidación democrática, gracias a la inclusión de transformaciones que buscaban configurar un régimen político más pluralista, abierto y competitivo (Dávila, 2002)

Autores como Przeworski, Ortega y Rapoport (1997) han considerado que la permanencia de la democracia se ve afectada por circunstancias económicas relacionadas con el lento crecimiento y los altos niveles de desigualdad en la distribución del ingreso, así como por fallas institucionales que implican problemas de representación. Sin embargo, este estudio apoya la idea de que la mayoría de los colombianos considera que cualquier cambio político o económico que permita mejorar dichas condiciones debe realizarse dentro de los parámetros de procedimientos democráticos.

En línea con lo anterior, según la misma encuesta Latinobarómetro, alrededor del 50\% de los encuestados en 2020 y del $57 \%$ de los encuestados en 2015 consideraron que la democracia es preferible a otras formas de gobierno. Esto es coherente con los hallazgos presentados por el Barómetro de las Américas (2010), según el cual, “el apoyo a la democracia, el apoyo al sistema político y la satisfacción con la democracia, en general, no han disminuido sustancialmente en la mayoría de los países de las Américas como consecuencia de la crisis" (p. 54). En efecto, según este mismo estudio, los predictores más importantes del apoyo a la democracia son el nivel educativo y la edad. Lo anterior es coherente con los resultados de este artículo: independientemente del nivel de ingreso, la mayoría de las personas prefieren votar siempre en lugar solo protestar.

\section{COHERENCIA ENTRE CONDUCTA Y LO QUE SE REPORTA EN LA ENCUESTA}

Los hallazgos de este estudio son coherentes con lo encontrado en otros estudios y respaldan la existencia de una relación de complementariedad entre la protesta y el voto para el caso de Colombia. Sin embargo, las cifras de participación electoral ponen un manto de duda sobre la coherencia entre las opiniones de los ciudadanos y su verdadero comportamiento. En particular, a pesar de que la encuesta de Latinobarómetro y la ECP muestran un apoyo a los sistemas electorales tradicionales como mecanismos idóneos para generar cambios en el país, el comportamiento real de los ciudadanos no está alineado con esta idea. En efecto, los altos niveles de abstencionismo, así como el aumento en los últimos años de los votos blancos y nulos, indican que los hábitos democráticos no son tan fuertes como la opinión ciudadana sobre la democracia. 
Por otro lado, las preferencias de los colombianos por los mecanismos de participación pueden cambiar si se presentan situaciones explosivas de descontento con el régimen democrático, debido por ejemplo a un escenario de retrocesos en materia económica o social en un contexto de altos niveles de corrupción política y administrativa, como lo demuestra la última ola de protestas, en abril y mayo de 2021, a raíz de la presentación de una reforma tributaria. Esta situación podría llegar a ser una amenaza para la estabilidad del sistema político debido a que la corrupción debilita las instituciones en lo que respecta a su cohesión y coherencia (pues pierden su capacidad de mediar intereses encontrados), a su autonomía (pues pueden ser instrumento de intereses particulares), y a su capacidad de adaptarse con rapidez a los cambios que implican los reclamos sociales y los procesos de modernización.

Además, las preferencias por las formas de participación política pueden cambiar a la luz del nuevo contexto político-social en el que se encuentra el país, caracterizado principalmente por la firma del acuerdo de paz con las FARC y el desarrollo de la agenda consignada en este acuerdo. El fin del conflicto tiende a fortalecer las reclamaciones sociales por los cauces democráticos y, por consiguiente, puede implicar un mayor nivel de conflictividad social. Los ciudadanos que antes no se manifestaban por razones como el miedo, la estigmatización de sus luchas o el desprestigio relacionado con la protesta dentro de la dinámica del conflicto, empezarán a realizar reclamos y peticiones, sin importar sus aspiraciones o agenda.

En este contexto, las organizaciones sociales ya existentes tienen la opción de dinamizarse y consolidarse para buscar con más fuerza sus objetivos y perfeccionar sus demandas sociales. Lo anterior es especialmente cierto para aquellos movimientos sociales que han tratado temas asociados transversalmente a las dinámicas del conflicto armado (minorías étnicas, problemas de género, derechos humanos, desarrollo social, etc.). Al mismo tiempo, pueden crearse nuevas redes de compromiso cívico, conformadas por personas que probablemente no se sienten tan identificadas con los grupos que ya existen.

Como lo constataron las protestas de noviembre de 2019 y las de 2021 en Colombia, todo lo anterior implica un mayor número de movilizaciones sociales, que además exhiben una mayor complejidad por la variedad de actores e intereses que involucran. Una ciudadania más crítica del desempeño de los procesos politicos (por ejemplo, porque tolera menos la corrupción), más exigente frente a los resultados de las instituciones y menos temerosa de salir a las calles tiene como consecuencia 
un aumento de la participación democrática no institucionalizada. Lo anterior puede desencadenar espirales de inestabilidad y decadencia política (debido a que los ciudadanos confían menos en la capacidad de los mecanismos institucionales, como el voto, para generar cambios), o, por el contrario, fortalecer la relación de complementariedad entre el voto y la protesta para mejorar la calidad de los procesos políticos y los resultados que los ciudadanos esperan de las instituciones.

Por último, las preferencias ciudadanas por las formas de participación dependen de los contextos políticos específicos de cada país, por lo que los resultados de este estudio no se pueden superponer a otros países de Latinoamérica. Futuras investigaciones deberán abordar cómo estas preferencias cambian en países que, por ejemplo, superaron sus conflictos armados internos hace varias décadas, han sufrido un deterioro más profundo del sistema democrático o tienen sistema políticos más populistas y plebiscitarios.

\section{REFERENCIAS BIBLIOGRÁFICAS}

Archila, M. (2003). Colombia 1975-2000: De crisis en crisis. Contexto. En M. Archila, A. Delgado et al. (eds.), 25 años de luchas sociales en Colombia (pp. 13-43). Bogotá: Cinep.

Arévalo B., J. (2018). State capacity and support for democracy: Challenges and opportunities for post conflict Colombia. Revista de Economía Institucional, 20(39), 159-186.

Ball, C. (2009). What is transparency? Public Integrity, 4(11), 293-308.

BBC News. (2016). Panama papers affair widens as database goes online, [https://www.bbc.com/news/world-latin-america-36249982].

Bonifácio, R. y Paulino, R. (2015). Corruption and political participation in the Americas and the Caribbean. Brazilian Political Science Review, 9(2), 54-80.

Brady, H., Schlozman, K. y Verba, S. (1995). Voice and equality: Civic voluntarism in American politics. Londres: Harvard University Press.

Canache, D. y Allison, M. E. (2005). Perceptions of political corruption in Latin American democracies. Latin American Politics and society, 47(3), 91-111.

Castañeda, J. G. (2016). Latin Americans stand up to corruption: The silver lining in a spate of scandals. Foreign Affairs, 1(95), 145-152.

Cinep. (2016). Informe especial. Movilización por la Paz en Colombia: una infraestructura social clave para el posacuerdo, Bogotá: Cinep/ Programa por la Paz.

Costas-Pérez, E. (2013). The effects of political corruption on turnout: Mobilization or disaffection? Elenacostasperez.Com, 2-22.

CNN. (2019). ¿Primavera latinoamericana? 2019, un año de protestas en la región, [https://cnnespanol.cnn.com/2019/11/22/primaveralatinoamericana-2019-un-ano-de-protestas-en-la-region/].

Dane. (2019). Encuesta de Cultura Política. 
Stockemer, D., LaMontagne, B. y Scruggs, L. (2012). Bribes and ballots: The impact of corruption on voter turnout in democracies. International Political Science Review, 34(1), 74-90.

Dávila L. de G., A. (2002). Democracia pactada: El frente nacional, y el proceso constituyente del 91. Lima: Institut français d'études andines, Alfaomega.

DW. (2018a). Perú: nuevas movilizaciones contra la corrupción, [https://p. dw.com/p/32EEV].

DW. (2018b). Manifestación universitaria revive las protestas contra Maduro. DW, [https://p.dw.com/p/38h4u].

Easton, D. (1975). A re-assessment of the concept of political support. British Journal of Political Science, 5(04), 435-457.

Fukuyama, F. (2014). Political order and political decay: From the Industrial Revolution to the globalisation of democracy. Londres: Farrar, Straus y Giroux - Macmillan.

Gallas, D. (2019). Brazil's Odebrecht corruption scandal explained. BBC News, [https://www.bbc.com/news/business-39194395].

Garay S., L. J. y Salcedo A., E. (2014). Narcotráfico, corrupción y Estados. Bogotá: Debate.

Gingerich, D. W. (2009). Corruption and political decay: Evidence from Bolivia. Quarterly Journal of Political Science, 4(1), 1-34.

Huntington, S. P. (1965). Political development and political decay. Cambridge University Press, 17(3), 386-430.

Inman, K. y Andrews, J. T. (2015). Corruption and voting in Senegal: Evidence from experimental and survey research. African Journal of Political Science and International Relations, 9(3), 100-114.

Ionescu, L. (2013). The influence of corruption on political participation. Economics, Management, and Financial Markets, 8(4), 184-189.

Kaufmann, D. y Kraay, A. (2021). Worldwide governance indicators, [https://info.worldbank.org/governance/wgi/].

Kostadinova, T. (2013). Corruption and political participation. Testing Models of Voting and Protesting, 1, 1-28.

Kriele, M. (1988). Introducción a la teoría del Estado: Fundamentos históricos de la legitimidad del Estado constitucional democrático. Buenos Aires: Depalma.

Lake, R. L. D. y Huckfeldt, R. (1998). Social capital, social networks, and political participation. International Society of Political Psychology, 19(3), 567-584.

Leighley, J. E. (1995). Attitudes, opportunities: A field essay and incentives on political participation. Political Research Quarterly, 48(1), 181-209.

Lipset, S. M. (1994). Current revolutions. American Journal of Economics and Sociology, 53(1), 69-105.

Lissardy, G. (2019). Protestas en América Latina: 'Vamos a seguir con manifestaciones hasta que los pueblos crean que se gobierna para ellos y no para un puñado'. BBC Mundo, [https://www.bbc.com/mundo/ noticias-america-latina-50137163]. 
Machado, F., Scartascini, C. y Tommasi, M. (2011). Political institutions and street protests in Latin America. Journal of Conflict Resolution, 55(3), 340-365.

Mainwaring, S. y Pérez Liñán, A. (2015). Cross-currents in Latin America. Journal of Democracy, 26(1), 114-127.

Miranda, B. (2019). Paro nacional en Colombia: cómo se viven las protestas (y qué piden) en algunas de las regiones más descuidadas del país, [https://www.bbc.com/mundo/noticias-america-latina-50606535].

Miranda, B. (2019). Protestas en Bolivia tras la cuestionada victoria de Evo Morales: cómo se radicalizaron las manifestaciones y la violencia en el país. BBC Mundo, [https://www.bbc.com/mundo/noticiasamerica-latina-50333889].

Moseley, M. W. (2015). Contentious engagement: Understanding protest participation in Latin American democracies. Journal of Politics in Latin America, 7(3), 3-48.

Nie, N. H., Powell, G. B. y Prewitt, K. (1969). Social structure and political participation: Developmental relationships. American Political Science Review, 63(2), 361-378.

Norris, P. (2002). Democratic Phoenix: Reinventing political activism. Cambridge, UK: Cambridge University Press.

Norris, P. (2011). Democratic deficit. Critical citizens revisited. Cambridge: Cambridge University Press.

Olsson, S. A. (2014). Corruption and political participation: A multilevel analysis, [http://www.qog.pol.gu.se/digitalAssets/1502/1502082_2014_12_arkhede-olsson.pdf].

Ortiz E., D. y Calixto, L. C. (2018). Medición de la corrupción regional en Colombia: una propuesta de indicadores a partir de registros de organismos de investigación y control. En J. C. Henao y C. Isaza E. (eds.), Corrupción en Colombia, t. 1: Corrupción, politica y sociedad (pp. 223-270). Bogotá: Universidad Externado de Colombia.

Powell, G. B. (1982). Contemporary democracies: Participation, stability, and violence. Cambridge, MA: Harvard University Press.

Pring, C. y Vrushi, J. (2019). Global corruption barometer: Latinamerica $\&$ The Caribbean, 2019. Transparency International.

Przeworski, A., Ortega, J. M. y Rapoport, S. G. (1997). Una defensa de la concepción minimalista de la democracia. Revista Mexicana de Sociología, 59(3), 3-36.

Rojas R., R. (2018). ¿Qué pasa en Nicaragua? [https://p.dw.com/p/2wafu].

Rooij, E. A. y Reeskens, T. (2014). Conventional and unconventional political participation. En W. Arts y L. Halman (eds.), Value contrasts and consensus in present-day Europe (pp. 185-212). Boston: BRILL.

Rúa D., C. (2013). La legitimidad en el ejercicio del poder político en el estado social de derecho. Una revisión desde el caso colombiano. Revista Ius et Praxis, 19(2), 85-122.

Seligson, M. A. (2002). The impact of corruption on regime legitimacy: A comparative study of four Latin American countries. Journal of Politics, 2(64), 408-433. 
Stockemer, D., LaMontagne, B. y Scruggs, L. (2012). Bribes and ballots: The impact of corruption on voter turnout in democracies. International Political Science Review, 34(1), 74-90.

Tarrow, S. G. (2011). Power in movement: Social movements and contentious politics revised and updated third edition. Cambridge: University Press.

Tilly, C. y Tarrow, S. (2015). Contentious politics. Nueva York: Oxford University Press.

Transparency International. (2020a). What is corruption? [https://www. transparency.org/en/what-is-corruption].

Transparency International. (2020b). Corruption Perceptions Index 2019.

Warren, M. E. (2004). What does corruption mean in a democracy? American Journal of Political Science, 48(2), 328-343.

Warren, M. E. (2006). Political corruption as duplicitous exclusion. Political Science and Politics, 3(4), 803-807.

Wolfinger, R. y Rosenstone, S. (1980). Who votes? New Haven: Yale University Press. 